\title{
The optimum sodium hydroxide concentration for high strength pla-rice straw
} composites

\section{Melissa Augustine Saidi ${ }^{1}$, Alexander Gorin ${ }^{1}$, Kok Heng Soon ${ }^{1}$ and Elammaran Jayamani $^{1}$}

${ }^{1}$ Faculty of Computing, Engineering and Science, Swinburne University of Technology

(Sarawak Campus), Jalan Simpang Tiga, 93350 Kuching, Sarawak, Malaysia

*Email: masaidi@swinburne.edu.my

Phone: +6082416353

\begin{abstract}
Most of the recent researches on sodium hydroxide $(\mathrm{NaOH})$ treatment discusses on only the improvement in the properties of natural fibre composites. However, there is a potential in studying the effects of sodium hydroxide treatment even further by identifying the optimum $\mathrm{NaOH}$ concentration in order to achieve maximum improvement in the properties of the natural fibre composites. This work reports the development of a composite material derived from both renewable resource and biodegradable material with the emphasis to identify the optimum $\mathrm{NaOH}$ treatment condition to achieve maximum improvement in the flexural strength of poly-lactic acid (PLA) reinforced with rice straw (RS) fibres. The RS fibres were treated with different $\mathrm{NaOH}$ concentrations $(1.25,2.5,3.75,5$ and $6.25 \mathrm{~mol} / \mathrm{L})$ and the optimum $\mathrm{NaOH}$ concentration was $5 \mathrm{~mol} / \mathrm{L}$ of $\mathrm{NaOH}$ where the flexural strength of the PLA/RS fibres were improved by $185 \%$. Thus, it can be concluded that with the optimum $\mathrm{NaOH}$ concentration, a strong adhesion between the PLA matrix and the RS fibre which resulted in the improvement in the flexural strength.
\end{abstract}

Keywords: Poly-lactic acid; rice straw fibre; sodium hydroxide; flexural properties.

\section{INTRODUCTION}

Many scientific research studies on polymer matrices reinforced with natural fibres composites have emerged due to its high performance comparable to those of synthetic fibres, apart from the low cost and the environmental friendliness associated with natural fibres $[1,2]$. These natural fibre composites exhibit wide range of mechanical properties which depends on their interface strength which dictates the transfer of applied stress from the matrix to the fibre. In addition, there is also a lack in interfacial bonding between the hydrophilic fibres and the hydrophobic matrix due to their lack of compatibility [3]. Interfacial bond between the natural fibre and matrix plays an important role in determining the mechanical properties. Natural fibre composites that exhibited improved properties are alkali treated composites compared to untreated composites [4]. Thus, one of the ways which could improve the interfacial bonding is using sodium hydroxide treatment to modify the surface structure of the fibre which could potentially improve the interfacial strength of the fibres-matrix [5]. 
The flexural strength of recycled low-density polyethylene reinforced with crushed Luffa cylindrica fibres decreased when the $\mathrm{NaOH}$ concentrations increased from $0 \mathrm{wt} \%$ to $4 \mathrm{wt} \%$. However, it began to increase with increasing $\mathrm{NaOH}$ concentrations from $8 \mathrm{wt} \%$ to $10 \mathrm{wt} \%$ [6]. Still, the $\mathrm{NaOH}$ treatment was not able to improve the flexural strength of the composites as the untreated crushed luffa cylindrica fibre/rLDPE composites showed a higher flexural strength.

On the other hand, with $\mathrm{NaOH}$ treatment, hemp fibres were able to reinforce the hemp/polypropylene (PP) composites. There are slight improvements compared to untreated hemp/PP composites when the hemp fibres are treated with $5 \mathrm{wt} \%$ and 10 wt $\% \mathrm{NaOH}$ concentration [7]. However, there are no indications of optimum $\mathrm{NaOH}$ concentration where the maximum improvement in the flexural strength could be observed.

The optimum $\mathrm{NaOH}$ concentration where maximum improvement in the flexural strength could be observed is at $1 \mathrm{wt} \%$ for the treatment of bagasse fibres. Compared to the untreated fibre composites, its flexural strength was $16 \%$ greater. As the $\mathrm{NaOH}$ concentration increased, the flexural strength starts to decrease due to the damage in the fibre inter-laminar bond [8,9]. Thus, it can be proven that it is crucial to achieve optimum $\mathrm{NaOH}$ concentration for the reinforcement of the material to attain maximum improvement in the flexural properties. The optimum $\mathrm{NaOH}$ concentration however, is different for different fibres as it reacts differently with $\mathrm{NaOH}$. The flexural properties of treated kenaf/epoxy composites were improved by $36 \%$ with 6 wt $\% \mathrm{NaOH}$ concentration compared to untreated fibres [10].

There is a gap in the natural fibre composite research field where there are very few researches which focuses on $\mathrm{NaOH}$ treatment of RS fibres. Thus, this study will be investigating the optimum $\mathrm{NaOH}$ concentration for the improvement in the flexural strength of poly-lactic acid reinforced with rice straw fibres.

\section{EXPERIMENTAL SET UP}

The poly-lactic acid (PLA) powder used in this study was supplied by Shenzhen Esun Industrial Co Ltd, China. It is graded PLA AI-1001 powder with a density of $1.25 \mathrm{~g} / \mathrm{cm}^{3}$ and a melt index of around $10-12 \mathrm{~g} / 10 \mathrm{~min}\left(190{ }^{\circ} \mathrm{C} / 2.16 \mathrm{~kg}\right)$. The rice straw (RS) fibres were obtained from a local farmer from Kampung Asajaya Laut, Kota Samarahan Malaysia and only the main culm which is the innermost part of the RS fibres was further processed. It was grinded in a milling machine and then sieved in a motorized test sieve shaker at around 10-20 minutes to segregate them according to different sizes. Only loose RSF that passed through the $1.18 \mathrm{~mm}$ diameter sieve (where the length of the RS fibres ranges from 0.4 to $0.8 \mathrm{~mm}$ ) were used in this study. The RSF were cleaned and dried for 24 hours in a drying oven with air circulation at a temperature of $80{ }^{\circ} \mathrm{C}$.

The RS fibres were then chemically treated with sodium hydroxide $(\mathrm{NaOH})$ with different concentration and different soaking time to examine the effect on the flexural strength of the PLA/RSF composite. Various $\mathrm{NaOH}$ concentrations used for this study are $1.25,2.5,3.75,5$ and $6.25 \mathrm{~mol} / \mathrm{L}$ of $\mathrm{NaOH}$. The $\mathrm{NaOH}$ solutions were prepared by dissolving specific quantity of $\mathrm{NaOH}$ pellets according to table 1 in $800 \mathrm{ml}$ of distilled water. Then, $40 \mathrm{~g}$ of RS fibres were soaked in the $\mathrm{NaOH}$ solution. After 30 minutes, the soaked rice straw fibres were rinsed with water to remove the alkali residues and then dried in the convection oven at $100{ }^{\circ} \mathrm{C}$ for 5 hours. 
Table 1. The $\mathrm{NaOH}$ concentration (mol/L) with the amount of alkali $(\mathrm{g})$.

\begin{tabular}{cc}
\hline $\begin{array}{c}\mathrm{NaOH} \text { concentration } \\
(\mathrm{mol} / \mathrm{L})\end{array}$ & $\begin{array}{c}\text { Amount of alkali } \\
(\mathrm{g})\end{array}$ \\
\hline 1.25 & 40 \\
2.5 & 80 \\
3.75 & 120 \\
5 & 160 \\
6.25 & 200 \\
\hline
\end{tabular}

The flexural test specimens were prepared by compression moulding using a 30 ton hydraulic hot press machine. Firstly, the hot press plates of the machine were heated from room temperature to the pressing temperature which is $150{ }^{\circ} \mathrm{C}$. Prior to the compression, the mixture of PLA and RS fibres were prepared as $10 \mathrm{vol} \%$ of RS fibres (weighing around $1 \mathrm{~g}$ ) was filled in the cavities in a stainless steel mould. The specimens were then sandwiched within the hot press plates with no pressure applied to heat up the mould for around 5 minutes and then a pressure of $7 \mathrm{MPa}$ was applied onto the specimens. After keeping at the temperature and pressure for 16 minutes, the specimens were cooled to room temperature and then taken out from the mould.

\section{TESTING AND CHARACTERIZATION}

Flexural test was conducted on an UTM107 according to the ASTM D790 standard. Each specimen has a dimension of $80 \mathrm{~mm} \times 5 \mathrm{~mm} \times 12.5 \mathrm{~mm}$. Specimens were loaded in three-point bending and tested flatwise on a support span to depth ration of 16( \pm 1$): 1$ with a cross head speed of $1 \mathrm{~mm} / \mathrm{min}$. The flexural strength in a three point bending test is given by Equation 1.

$$
\sigma_{\max }=\frac{3 P L}{b d^{2}}
$$

Where $P$ is the maximum load $(\mathrm{N}), L$ is the span $(\mathrm{mm}), b$ and $d$ is the width and thickness of the specimen. For the scanning electron microscope (SEM) analysis, the surface and the cracks from the specimens were observed by using Hitachi TM3030.

\section{RESULTS AND DISCUSSION}

Figure 1 shows the flexural strength of PLA/RSF composite when treated with different concentration of $\mathrm{NaOH}$. It can be observed that the PLA/RSF which was treated with 5 $\mathrm{mol} / \mathrm{L}$ (equivalent to $20 \mathrm{wt} \%$ ) of $\mathrm{NaOH}$ has the highest flexural strength which is 48.06 $\mathrm{N} / \mathrm{mm}^{2}$ and it is higher than the flexural strength of untreated RSF by $185 \%$. 


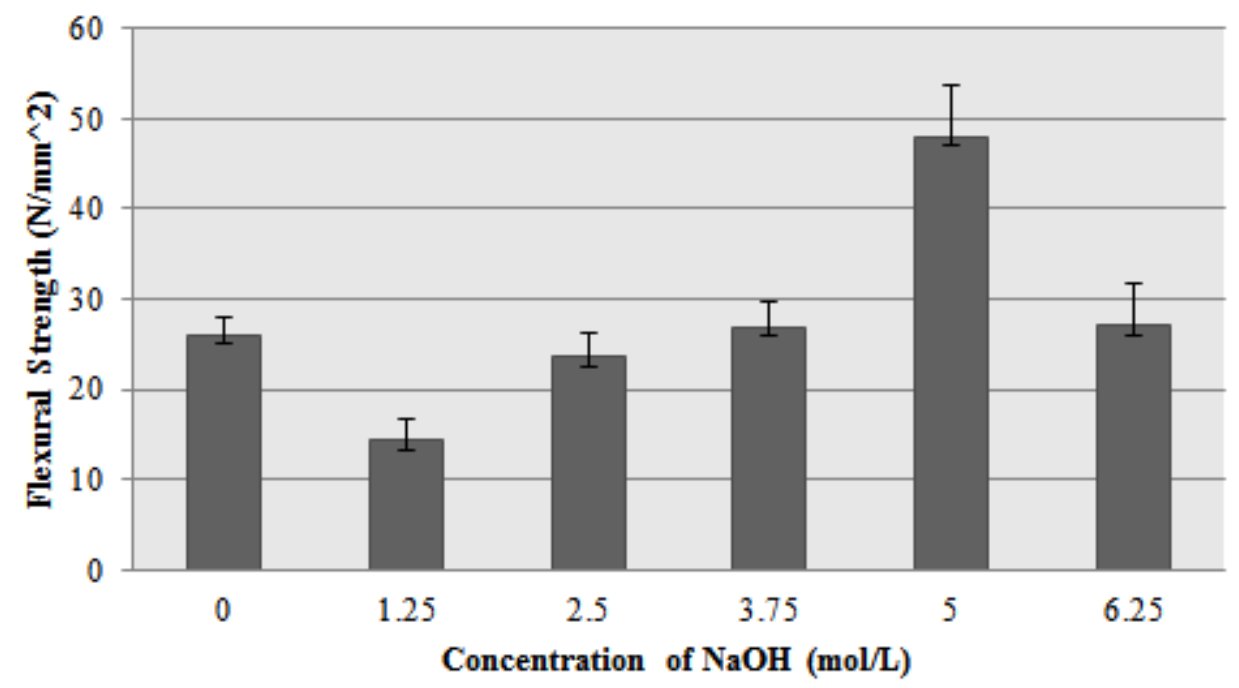

Figure 1. Flexural strength for the sodium hydroxide treated PLA/RS fibre composites.

The enhancement in the flexural strength of the sodium hydroxide treated fibre is due to the improvement in the fibre to matrix interaction [6,7]. A process called retting action is the removal of the waxy layers on the fibre surface with the assistance of $\mathrm{NaOH}$ solution aided in forming better bonding between the fibres and the matrix polymer $[6,10]$. This is an important step to obtain better quality composites as untreated fibres caused stress concentrations and early fracture of the composite [11]. As the flexural properties of natural fibre composites are highly influenced by the fibre surface characteristics, $\mathrm{NaOH}$ treatment has highly enhanced the interfacial adhesion of the fibre with the matrix leading to better flexural properties compared to the untreated fibres.

At a higher $\mathrm{NaOH}$ concentration, it is expected that alkali treatment would decrease the strength of the composites [12]. However, in this study at $6.25 \mathrm{~mol} / \mathrm{L}$ (equivalent to $25 \mathrm{wt} \%$ ) of $\mathrm{NaOH}$, it resulted in a decrease in the flexural strength by $43.9 \%$ from the optimum sodium hydroxide concentration which is $20 \mathrm{wt} \%$. This could be due to chemical structure change in the cellulose where the cellulose molecular chains lose their crystalline structure as a result of $\mathrm{NaOH}$ treatment [12]. A higher $\mathrm{NaOH}$ concentration also damages the fibres inter-laminar bonding [9]. In comparison with other literatures, the optimum concentration of sodium hydroxide value for this study seems quite high. However, the soaking time for this study is limited to only 30 minutes whereas the soaking time of fibres in $\mathrm{NaOH}$ solution for the literatures ranges between 24 to 48 hours. Thus, the RS fibres are not damaged by the concentration instead it improves the strength of the PLA/RS fibres composite. 


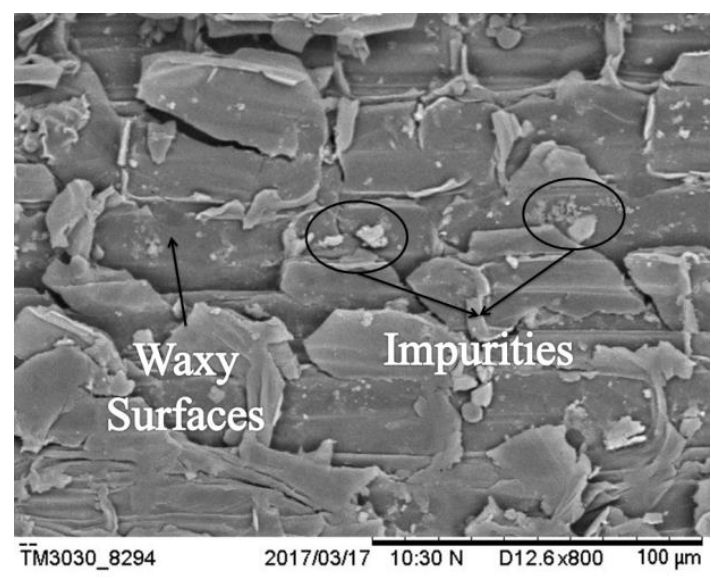

Figure 1. The surface of the untreated RS fibre (Magnification x800).

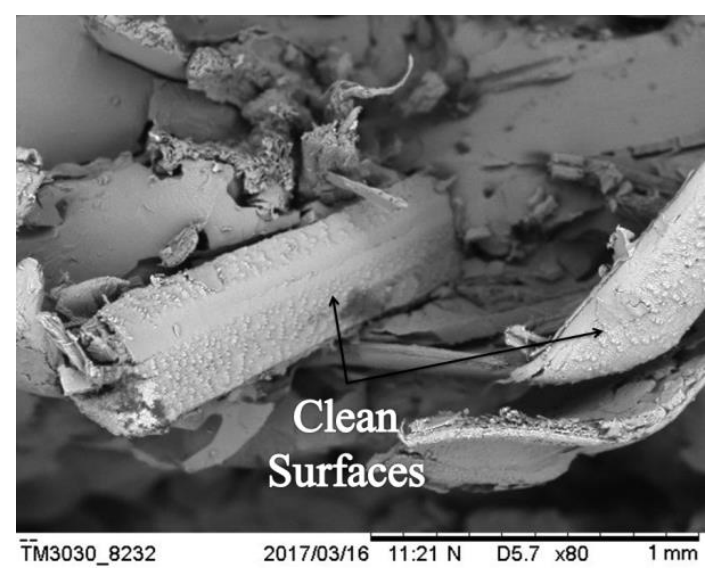

Figure 3. The untreated RS fibre/PLA composite after flexural testing (Magnification x80).

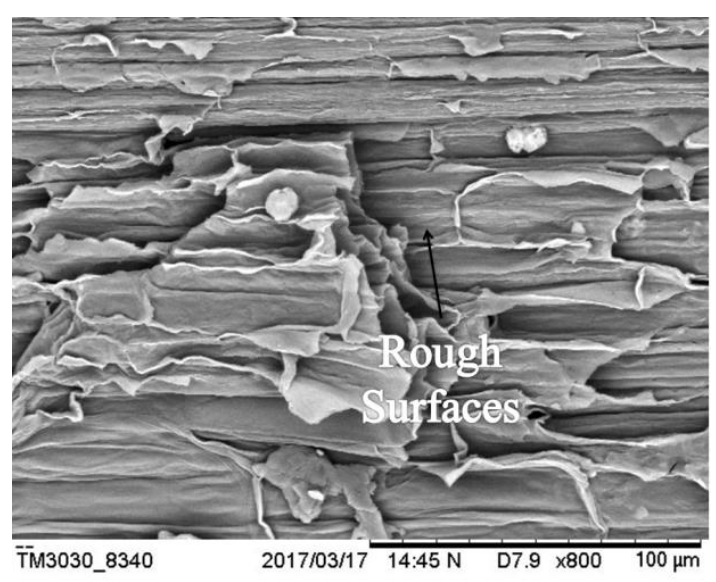

Figure 2. The surface of the $\mathrm{NaOH}$ treated RS fibre (Magnification x800).

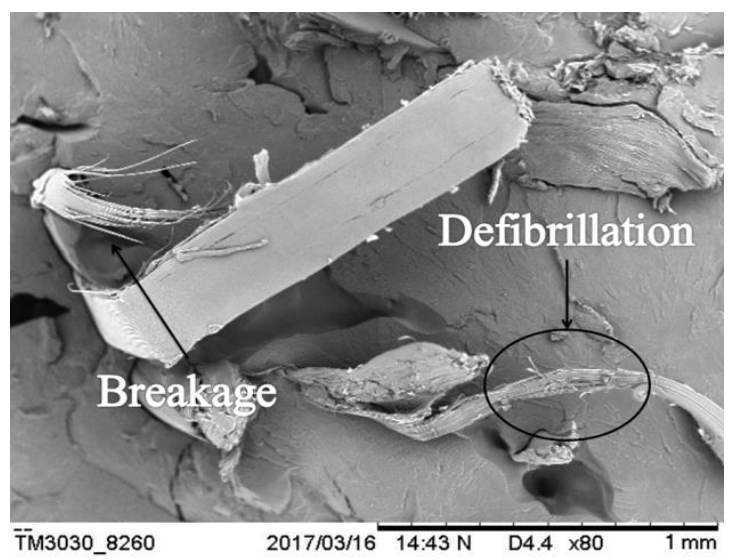

Figure 4. The $\mathrm{NaOH}$ treated RS fibre/PLA composite after flexural testing (Magnification x80).

To clarify the effect of $\mathrm{NaOH}$ treatment on RS fibre, morphological examinations were carried out using the scanning electron microscope on the untreated and $\mathrm{NaOH}$ treated fibres. From the scanning electron microscope (SEM) micrographs, it can be seen that the untreated RSF have uneven deposit impurities on its surface (Figure 2) but the sodium hydroxide treated RSF has cleaner but rougher surface (Figure 3) [13]. It can also be observed that there are presence of waxy substances and impurities on the untreated fibre surface and these waxy substances contributed to ineffective fibre-matrix bonding and poor surface wet out $[1,13,14]$. The $\mathrm{NaOH}$ treatment has increased the surface roughness by eliminating the waxy substances and distributing the hydrogen bonding in the network structure to provide additional sites for mechanical interlocking. This in result increases effective surface area available for contact with the matrix polymer $[7,8]$.

It can be seen from Figure 4 that the surface of the RS fibre is clean as the RS fibre could be pulled out as there is an ineffective fibre-matrix bonding. There are also 
no traces of PLA matrix on the surface of the RS fibre which means that there is poor surface wet out. However, in Figure 5, the $\mathrm{NaOH}$ treatment causes defibrillation which breaks down the composite fibre bundle into smaller fibres which has increased effective surface area available for contact with the matrix [1]. It can also be observed that there is a breakage in Figure 5 which means the stress was transferred from the PLA matrix to the RS fibre and this proves the effectiveness of the $\mathrm{NaOH}$ treatment that improves the adhesion of the RS fibre and the PLA matrix.

\section{CONCLUSION}

The flexural strength of the PLA/RS fibre composites improved when the RS fibres were treated with $\mathrm{NaOH}$ compared to untreated RS fibres. The maximum improvement in the flexural strength of the PLA/RS fibre is at $5 \mathrm{~mol} / \mathrm{L}$ (equivalent to $20 \mathrm{wt} \%$ ) of $\mathrm{NaOH}$ where it can be concluded to be the optimum $\mathrm{NaOH}$ concentration for the $\mathrm{NaOH}$ treatment of RS fibres where the flexural strength is $48.06 \mathrm{~N} / \mathrm{mm}^{2}$.

\section{ACKNOWLEDGEMENTS}

The authors are grateful to the Ministry of Education Malaysia (MOE) for providing financial assistance under the FGRS grant scheme (FRGS/2/2013/TK04/SWIN/03/1).

\section{REFERENCES}

[1] Rokbi, M, Osmani, H, Imad, A \& Benseddiq N. Effect of chemical treatment on flexure properties of natural fiber-reinforced polyester composite.Procedia Engineering. 2011;10:2092 - 2097.

[2] Rout, J, Misra, M, Tripathy, S, Nayak, S \& Mohanty A. The influence of fibre treatment on the performance of coir-polyester composites. Composites Science and Technology.2001;61(9):1303 - 1310.

[3] Mwaikambo L \& Ansell M.The effect of chemical treatment on the properties of hemp, sisal, jute and kapok fibres for composite reinforcement. Macromolecular Materials and Engineering.1999;272(1):108-116.

[4] Akos Noel I, Mat Uzir Wahit \& Abdirahman A Yussuf. Effect of fiber reinforcement on mechanical and thermal properties of $\operatorname{poly}(\varepsilon-$ caprolactone)/poly(Lactic Acid) blend composites. Fibers and Polymers.2014; 15(3):572-584.

[5] Prasad GE, Gowda BK \& Velmurugan R. 2017 Comparative study of impact strength characteristics of treated and untreated sisal polyester composites. Procedia Engineering.2017;173:778-785.

[6] Ubi PA \& Asipita SAR. Effect of sodium hydroxide treatment on the mechanical properties of crushed and uncrushed luffa cylindrica fibre reinforced rLDPE composites. International Journal of Materials and Metallurgical Engineering.2015;9;203-208.

[7] Sullins T, Pillay S, Komus A \& Ning H.Hemp fibre reinforced propylene composites: The effects of material treatments. Composites Part B: Engineering, 2017;114:15-22. 
[8] Cao Y, Shibata S \& Fukumoto I.Mechanical properties of biodegradable composites reinforced with bagasse fibre before and after alkali treatments. Composites Part A: Applied Science and Manufacturing, 2006;37(3):423-429.

[9] Mohd Suhairil Meon, Muhamad Fauzi Othman, Husain H, Muhammad Fairuz Remeli \& Mohd Syahar Mohd Syawal. 2012 Improving tensile properties of kenad fibers treated with sodium hydroxide. Procedia Engineering.2012;41: 1587-1592.

[10] Yousif B, Shalwan A, Chin C \& Ming K. Flexural properties of treated and untreated kenaf/epoxy composites. Materials \& Design. 2012; 40: 378-385.

[11] Weyenberg IVd, Ivens J, Coster AD, Kino B, Baetens E \& Verpoest I. Influence of processing and chemical treatment of flax fibres on their composites. Composites Science and Technology. 2003;63(9):1241-1246.

[12] Gomes A, Matsuo T, Goda K \& Ohgi J. Development and effect of alkali treatment on tensile properties of curaua fibre green composites. Composites Part A: Applied Science and Manufacturing.2007;38(8):1811-1820.

[13] Nor Azwin Ahad, Noraziana Parimin, Norsuria Mahmed, Ibrahim SS, Khairul Nizzam \& Ho Y. 2009 Effect of chemical treatment on the surface of natural fibre. Journal of Nuclear and Related Technologies.2009; 6; 155-158.

[14] Vilay V, Mariatti M, Taib RM \& Todo M. Effect of fibre surface treatment and fibre loading on the properties of bagasse fibre-reinforced unsaturated polyester composites. Composites Science and Technology. 2008;68(3-4): 631-638. 